\title{
Can we predict the clinical outcome of arthroscopic partial meniscectomy? A systematic review
}

\author{
Susanne M Eijgenraam, ${ }^{1,2}$ Max Reijman, ${ }^{1}$ Sita M A Bierma-Zeinstra, ${ }^{1,3}$ \\ Daan T van Yperen, ${ }^{1}$ Duncan E Meuffels ${ }^{1}$
}

- Additional material is published online only. To view, please visit the journal online (http://dx.doi.org/10.1136/ bjsports-2017-097836).

${ }^{1}$ Department of Orthopedic Surgery, Erasmus MC, University Medical Centre Rotterdam, Rotterdam, The Netherlands ${ }^{2}$ Department of Radiology \& Nuclear Medicine, Erasmus MC, University Medical Centre Rotterdam, Rotterdam, The Netherlands

${ }^{3}$ Department of General Practice, Erasmus MC, University Medical Centre Rotterdam, Rotterdam, The Netherlands

Correspondence to Dr Duncan E Meuffels, Department of Orthopedic Surgery, Erasmus MC, University Medical Centre Rotterdam, 3015 CE Rotterdam, Netherlands;

d.meuffels@erasmusmc.nl

Accepted 30 October 2017 Published Online First 28 November 2017

Check for updates

To cite: Eijgenraam SM, Reijman M, BiermaZeinstra SMA, et al. Br J Sports Med

2018;52:514-521.

\begin{abstract}
NHS-Prospero registration number 42016048592

Objective In order to make a more evidence-based

selection of patients who would benefit the most from arthroscopic partial meniscectomy (APM), knowledge of prognostic factors is essential. We conducted a systematic review of predictors for the clinical outcome following APM.
\end{abstract}

Design Systematic review

Data sources Medline, Embase, Cochrane Central

Register, Web of Science, SPORTDiscus, PubMed

Publisher, Google Scholar

Inclusion criteria Report an association between factor(s) and clinical outcome; validated questionnaire; follow-up $>1$ year.

Exclusion criteria $<20$ subjects; anterior cruciate ligament-deficient patients; discoid menisci; meniscus repair, transplantation or implants; total or open meniscectomy.

Methods One reviewer extracted the data, two reviewers assessed the risk of bias and performed a bestevidence synthesis.

Results Finally, 32 studies met the inclusion criteria. Moderate evidence was found, that the presence of radiological knee osteoarthritis at baseline and longer duration of symptoms (>1 year) are associated with worse clinical outcome following APM. In addition, resecting $>50 \%$ of meniscal tissue and leaving a nonintact meniscal rim after meniscectomy are intra-articular predictive factors for worse clinical outcome. Moderate evidence was found that sex, onset of symptoms (acute or chronic), tear type or preoperative sport level are not predictors for clinical outcome. Conflicting evidence was found for the prognostic value of age, perioperative chondral damage, body mass index and leg alignment. Summary/conclusion Long duration of symptoms (>1 year), radiological knee osteoarthritis and resecting $>50 \%$ of meniscus are associated with a worse clinical outcome following APM. These prognostic factors should be considered in clinical decision making for patients with meniscal tears.

\section{INTRODUCTION}

${ }^{1}$ For many years, arthroscopic partial meniscectomy (APM) has been considered the gold standard for torn menisci, for both traumatic and degenerative tears. ${ }^{1}{ }^{2} 3$ Yearly, over 700000 APMs are performed in the USA. ${ }^{4}$ Although it remains one of the most common surgical procedures in many Western countries, ${ }^{5}$ several high-quality randomised controlled trials (RCTs) challenge the indications of APM. ${ }^{4-9}$ These trials, summarised in a recent systematic review, ${ }^{10}$ consistently show no benefit in function and pain relief of APM compared with physical therapy or sham surgery in patients with degenerative meniscal tears. Furthermore, there is a growing concern that patients who have undergone APM are at increased risk of developing knee osteoarthritis $(\mathrm{OA}) .^{2} 11$

Taking the results of the earlier mentioned RCTs and the concern about knee OA into account, a more evidence-based approach in patient selection for APM is needed. Instead of considering APM the standard of care, clinicians need to carefully select subgroup of patients with meniscal pathology who would likely benefit from APM. If one can predict the 'chance of success' (ie, patient-reported pain, physical function level) following APM based on patient characteristics, a more evidence-based patient selection can be made. In order to predict this chance of success, knowledge of prognostic factors is essential.

To the best of our knowledge, no systematic review of prognostic factors for the clinical outcome following APM has been conducted. We systematically reviewed all available literature, to determine the association between certain preoperative and operative variables and clinical outcome following APM. The purpose of this study was to identify prognostic factors for the clinical, patient-reported outcome of APM in patients with a meniscal tear.

\section{METHODS}

The reporting in this systematic review was conducted according to the Preferred Reporting Items for Systematic Reviews and Meta-Analyses statement. ${ }^{12}$ This study was registered in the International Prospective Register for Systematic Reviews of the National Institute for Health Research, no. 42016048592.

\section{Search strategy}

A health science librarian of our institution with extensive experience in the conduct of literature searching for systematic reviews assisted in designing and performing the search. We searched in Medline, Embase, Cochrane Central Register, Web of Science, SPORTDiscus, PubMed Publisher and Google Scholar for relevant articles (date of search: 16 September 2016). The following main keywords were used: knee, meniscus, meniscal tear, treatment and meniscectomy (see online supplementary appendix 1 for complete search). The articles types included in the search were RCTs and prospective or retrospective cohort studies. There was no date of publication restriction in the search. 


\section{Study selection}

The inclusion criteria for the present study were: (1) all subjects had to have a meniscal tear, confirmed by MRI/arthroscopy/X-ray with contrast, treated with APM; (2) subjects had to be aged over 18 years; (3) the study had to describe a correlation/association between one or more prognostic factors and patient-reported clinical outcome (from now on described as 'clinical outcome') of APM; (4) a validated patient-reported outcome measure had to be used; (5) there had to be a follow-up of at least 12 months and (6) the article had to be written in English, German, Dutch, French, Spanish or Swedish. We choose these languages because members of the project group were able to read these.

We excluded studies which (1) had $<20$ subjects; (2) included patients with anterior cruciate ligament (ACL) deficiency or with previous ACL reconstruction; (3) included patients with discoid menisci; (4) included patients undergoing meniscal repair; (5) included meniscus transplantation or meniscus implants; (6) included patients undergoing total meniscectomy; (7) included patients undergoing open meniscectomy and (8) included additional surgical interventions carried out at arthroscopy.

Two reviewers independently screened all titles and abstracts for eligibility. Disagreements were discussed and resolved by consensus. A third reviewer was asked in case of unsolved disagreement. Duplicate studies were removed using a validated method developed by the medical library of our institution, consisting of several steps. Furthermore, reference lists of all selected studies were searched to identify potential missed articles.

\section{Risk of bias}

To assess the potential risk of bias, two reviewers independently assessed each study using the Cochrane Collaboration's tool for assessing risk of bias of prognostic studies. ${ }^{13} 14$ This scoring list involves eight questions: two questions concerning selection bias, four questions concerning information bias and two questions concerning confounding. A low risk of bias was defined as (1) 'yes' to at least six out of eight questions and (2) at least one time 'yes' in each risk of bias category (selection bias, information bias, confounding). A moderate risk of bias was defined as (1) 'yes' to at least five out of eight questions and (2) at least one time 'yes' in two of the risk of bias categories. All other cases were considered as high risk of bias. The two reviewers discussed their findings and asked a third reviewer for consensus, if necessary.

\section{Data extraction}

Data regarding study design, level of evidence, number of patients, population characteristics, arthroscopic findings, outcome measurements, results and associated prognostic factors were extracted by one reviewer, using a standardised form.

\section{Best evidence synthesis}

The clinical and methodological homogeneity of the included studies was checked to evaluate whether a meta-analysis would be appropriate. If not, a best evidence synthesis was performed, using the algorithm developed by van Tulder et al. ${ }^{15-17}$ By summarising findings while taking the weight of the evidence into account in a standardised way, a best evidence synthesis provides conclusions based on the best available evidence. The following ranking of levels of evidence was used: (1) strong evidence is provided by two or more studies with low risk of bias and by generally consistent findings in all studies ( $\geq 75 \%$ of the studies reported consistent findings); (2) moderate evidence is provided by one low risk of bias study and two or more moderate/high risk of bias studies or by two or more moderate/ high risk of bias studies and by generally consistent findings in all studies ( $\geq 75 \%)$; (3) limited evidence is provided by one or more moderate/high risk of bias studies or one low risk of bias study and by generally consistent findings ( $\geq 75 \%)$; (4) conflicting evidence is provided by conflicting findings $(<75 \%$ of the studies reported consistent findings); (5) no evidence is provided when no studies could be found.

Besides overall analysis, subgroup analysis was performed regarding age (under and above 45 years).

\section{RESULTS}

\section{Search strategy}

We identified 5150 potentially relevant articles: 5146 by electronic search and 4 by reference tracking. After screening on title and abstract, 159 studies were considered to be potential eligible (figure 1). Full text of these studies was assessed, and 32 studies met our inclusion criteria and were included (see table 1 for study characteristics and main results).

\section{Characteristics of included studies}

We included $1 \mathrm{RCT}^{6} 4$ prospective follow-up studies ${ }^{18-21}$ and 27 retrospective studies. Overall, the included studies had allocated 4250 patients (range $26^{22}-1090^{23}$ ). The follow-up ranged from $1^{6202324}$ to $13^{2526}$ years. The mean age of patients of the included studies ranged from $19^{25}$ to $60^{27}$ years. Most articles included patients with all types of meniscal tears; however, two studies $^{28} 29$ only included radial tears, two studies ${ }^{3031}$ only horizontal tears, one study ${ }^{32}$ only included root-tears, one study ${ }^{33}$ only complex tears and one study ${ }^{34}$ only bucket-handle tears. Five studies excluded patients with a certain degree of chondral damage. Furthermore, 13 studies excluded patients with knee OA (mostly based on radiographs).

\section{Risk of bias of included studies}

For $2^{635}$ of the 32 included studies we found a low risk of bias. For the remaining studies, a moderate-to-high risk of bias was found. A risk of selection bias was found in $77 \%$ of the included studies, a risk of confounding in $94 \%$ and a risk of information bias in none of the studies. The agreement between reviewers in the risk of bias assessment was $98 \%$.

\section{Heterogeneity}

A considerable variability was found between included studies regarding study population, the definition of subgroups and outcome measures. Furthermore, clinical outcomes of individual subgroups were often inadequately described or lacking completely. Taking the considerable heterogeneity and lacking subgroup outcomes into account, pooling data and conducting a meta-analysis was not appropriate. Hence, qualitative analyses were performed, according to the best evidence synthesis principle.

\section{Prognostic factors}

In total, 13 different prognostic factors were identified and shown to be associated with clinical outcome following APM. Table 2 shows an overview of prognostic factors, which are described in at least two studies.

\section{Moderate evidence \\ Prognostic factors \\ Duration of symptoms}

Two studies ${ }^{36}$ evaluated the duration of symptoms in the context of clinical outcome. In one study, ${ }^{36}$ acute (symptoms existing $<12$ months) and chronic (symptoms existing $>12$ months) lesions are distinguished, one study ${ }^{37}$ defined a duration 


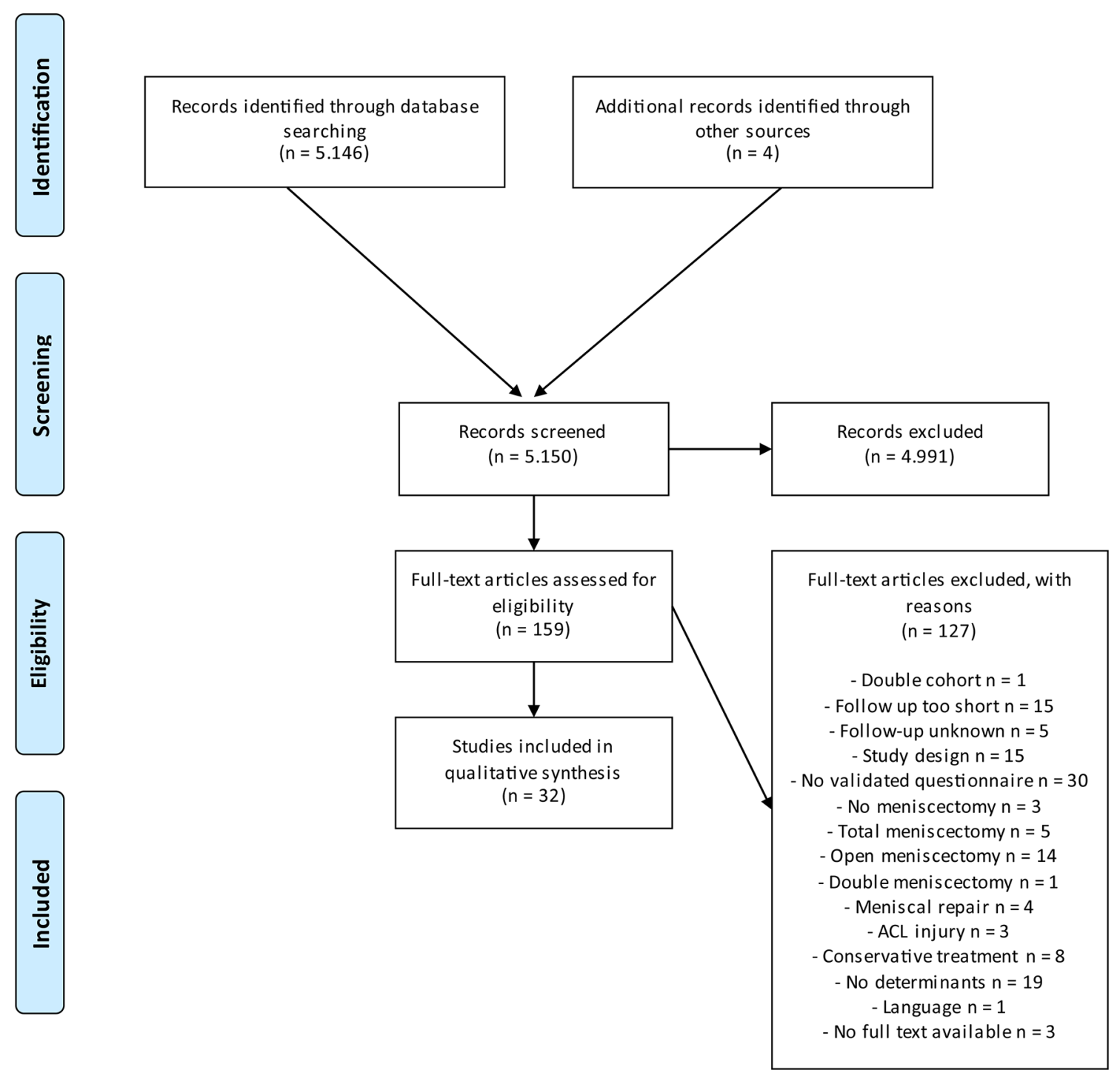

Figure 1 Flow diagram of identification, screening and selection of studies.

of 3 months or less as 'short', and longer than 3 months as 'long'. Both studies concluded that a shorter duration of symptoms is statistically significantly associated with better patient-reported outcome measures.

\section{Radiological knee $O A$ at baseline}

Two studies ${ }^{38} 39$ described the presence of radiological knee OA and its association with clinical outcome of APM. In one study, ${ }^{39}$ patients with no sign of knee OA (Kellgren and Lawrence ${ }^{40}$ grade 0) and patients with mild-to-moderate knee OA (Kellgren and Lawrence grade 1-2) were included. One study ${ }^{38}$ also included patients with severe knee OA (Fairbank $^{41}$ grade $>2$ ). Both studies reported a statistically significant smaller improvement of Lysholm knee scores in patients with radiological knee $\mathrm{OA}$ at baseline.

\section{Amount of resected tissue}

Six studies assessed the relationship between the amount of resected tissue during APM and clinical outcome. Five out of six studies reported a positive association between the amount of resected meniscal tissue and decreased patient-reported outcome measures. In two studies, ${ }^{25} 42$ a 'subtotal' procedure $(>50 \%$ resected, leaving a small rim of meniscal tissue) was found to result in worse clinical outcome than a 'partial' procedure ( $<50 \%$ of meniscal tissue resected). Other studies described the absence of the meniscal rim $^{43}$ or a preserved meniscal width of $<3 \mathrm{~mm}^{44}$ as a predictor for worse clinical outcome. In one study, ${ }^{45}$ the method for measuring the influence of this factor on clinical outcome was not further described. One study, ${ }^{46}$ which investigated the influence of the percentage of removed tissue in 31 knees with lateral meniscal tears, found no association with postoperative Lysholm scores.

\section{No prognostic factors}

Sex

The influence of sex on clinical outcome after APM was assessed in 10 articles. Eight of them reported no statistically significant association between sex and outcome. Two studies ${ }^{19} 20$ reported a worse outcome for women.

\section{Traumatic/non-traumatic onset}

The influence of onset, that is, traumatic versus non-traumatic, on outcome after APM was assessed in eight articles and seemed not to be a predictor for clinical outcome. Two studies ${ }^{27} 47$ reported a worse outcome for non-traumatic tears, based on 


\begin{tabular}{|c|c|c|c|c|c|}
\hline Group & Determinants & $\begin{array}{l}\text { Number of } \\
\text { studies }\end{array}$ & $\begin{array}{l}\text { Significant association with worse } \\
\text { outcome } L R / M R / H R^{*}: n \text { studies }\end{array}$ & $\begin{array}{l}\text { No significant relationship LR/ } \\
\text { MR/HR*: } \text { studies }\end{array}$ & Best evidence synthesis \\
\hline \multirow[t]{6}{*}{$\begin{array}{l}\text { Patient-related } \\
\text { factors }\end{array}$} & Older age at baseline & 11 & $\begin{array}{l}\text { LR: } 1^{35} \\
\text { MR: } 2^{3648} \\
\text { HR: } 2^{1972}\end{array}$ & HR: $6^{2022244373}$ & Conflicting evidence \\
\hline & Female sex & 10 & HR: $2^{1920}$ & $\begin{array}{l}\text { MR: } 3^{233648} \\
\text { HR: } 5^{2442434573}\end{array}$ & Moderate evidence \\
\hline & Higher body mass index & 7 & $\begin{array}{l}\text { MR: } 1^{23} \\
\text { HR: } 3^{243372}\end{array}$ & HR: $3^{202942}$ & Conflicting evidence \\
\hline & Longer duration of symptoms & 2 & $\begin{array}{l}\text { MR: } 2^{36} \\
\text { HR: } 1^{37}\end{array}$ & & Moderate evidence \\
\hline & Non-traumatic onset & 8 & HR: $2^{2747}$ & $\begin{array}{l}\text { LR: } 1^{6} \\
\text { MR: } 1^{30} \\
\text { HR: } 4^{42} 72-74\end{array}$ & Moderate evidence \\
\hline & Lower preoperative sport level & 4 & & $\begin{array}{l}\text { MR: } 1^{48} \\
\text { HR: } 3^{204243}\end{array}$ & Moderate evidence \\
\hline \multirow{5}{*}{$\begin{array}{l}\text { Intra-articular } \\
\text { factors }\end{array}$} & Leg malalignment & 3 & HR: $1^{38}$ & HR: $2^{2243}$ & Conflicting evidence \\
\hline & Type of meniscal tear & 9 & $\begin{array}{l}\text { Degenerative/complex tear: } \\
\text { MR: } 1^{36} \\
\text { Flap tear: } \\
\text { MR: } 1^{48}\end{array}$ & HR: $7^{22} 233143457273$ & Moderate evidence \\
\hline & $\begin{array}{l}\text { Presence of radiological knee } \\
\text { osteoarthritis at baseline }\end{array}$ & 2 & HR: $2^{3839}$ & & Moderate evidence \\
\hline & $\begin{array}{l}\text { Presence of chondral damage } \\
\text { during arthroscopy }\end{array}$ & 10 & $\begin{array}{l}\text { MR: } 1^{36} \\
\text { HR: } 5^{18-2033} 39\end{array}$ & $\begin{array}{l}\text { LR: } 1^{35} \\
\text { MR: } 1^{48} \\
\text { HR: } 2^{4373}\end{array}$ & Conflicting evidence \\
\hline & Resecting more tissue & 6 & $\begin{array}{l}\text { MR: } 2^{2544} \\
\text { HR: } 3^{424345}\end{array}$ & HR: $1^{46}$ & Moderate evidence \\
\hline
\end{tabular}

*LR, low risk of bias; MR, moderate risk of bias; HR, high risk of bias.

arthroscopic findings. However, six studies reported no statistically significant correlation.

\section{Preoperative sport level}

In four studies, preoperative sport level was assessed. Two studies $^{42} 43$ distinguished a recreational and competitive sport level, one study ${ }^{20}$ measured the hours of exercise per week and one study ${ }^{48}$ did not further specify study groups. None of the articles found a correlation between sport level and clinical outcome of APM.

\section{Type of meniscal tear}

In nine studies, the association between the type of meniscal tear and clinical outcome was assessed. Eight of them found no association, whereas one study ${ }^{36}$ reported a worse outcome for complex and for degenerative tears. None of the studies described a classification system used for the type of meniscal tears. Furthermore, a large variety among studies was found regarding the definition of subgroups (types of meniscal tears). The amount of subgroups ranged from two ${ }^{3648}$ to five. ${ }^{23}$

\section{Limited evidence}

An association between the location of the tear (medial vs lateral meniscus) and clinical outcome of APM was only described in one of our included studies ${ }^{43}$; in this study, no statistically significant difference was found between medial and lateral APMs. Regarding the side of knee, ${ }^{23}$ the location of chondral damage ${ }^{49}$ and perioperative synovial inflammation, ${ }^{21}$ no correlation with clinical outcome was found as well. Furthermore, one of the included studies ${ }^{20}$ assessed the predictive value of self-reported fitness at baseline and prior knee surgery and found a worse Lysholm score 1 year after APM for women with lower self-reported fitness. For men, no influence was found of self-reported fitness on clinical outcome. Prior knee injury resulted in a lower Lysholm after APM in women, in men however no such association was found.

\section{Conflicting evidence \\ Age at baseline}

The influence of age on clinical outcome following APM was investigated in 11 studies. In two studies, ${ }^{26} 48$ patients were divided into two groups: aged under 30 years and aged above 30 years. One article ${ }^{36}$ divided patients in a group under and above 40 years. In the remaining studies, the method for defining age subgroups was not specified. Five studies found a worse clinical outcome for older patients, and six studies did not find a statistically significant association.

\section{Body mass index}

Seven studies described the association between body mass index (BMI) and clinical outcome. Four of them reported a worse Lysholm score for overweight or obese patients. The remaining studies found no association between BMI and clinical outcome. When we looked at studies with patients aged above 45 years, we found evidence for the fact that there is no association between BMI and clinical outcome of APM.

\section{Leg malalignment}

The predictive value of leg malalignment was described in three studies. One of them ${ }^{38}$ reported a statistical significantly worse modified Lysholm score for patients with a valgus malalignment (tibiofemoral angle more than four degrees on anteroposterior full leg radiograph). However, two studies ${ }^{22} 43$ found no 


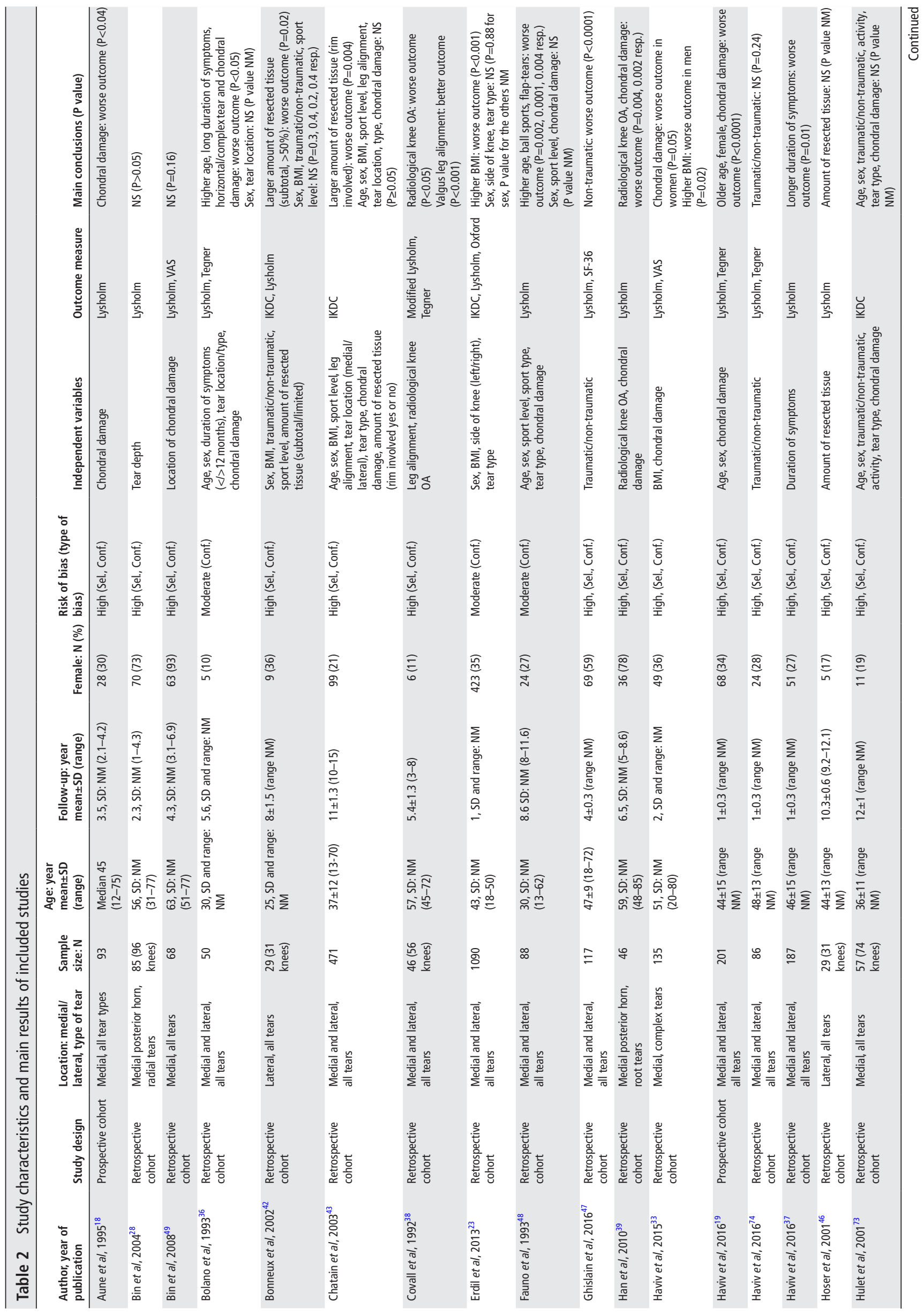




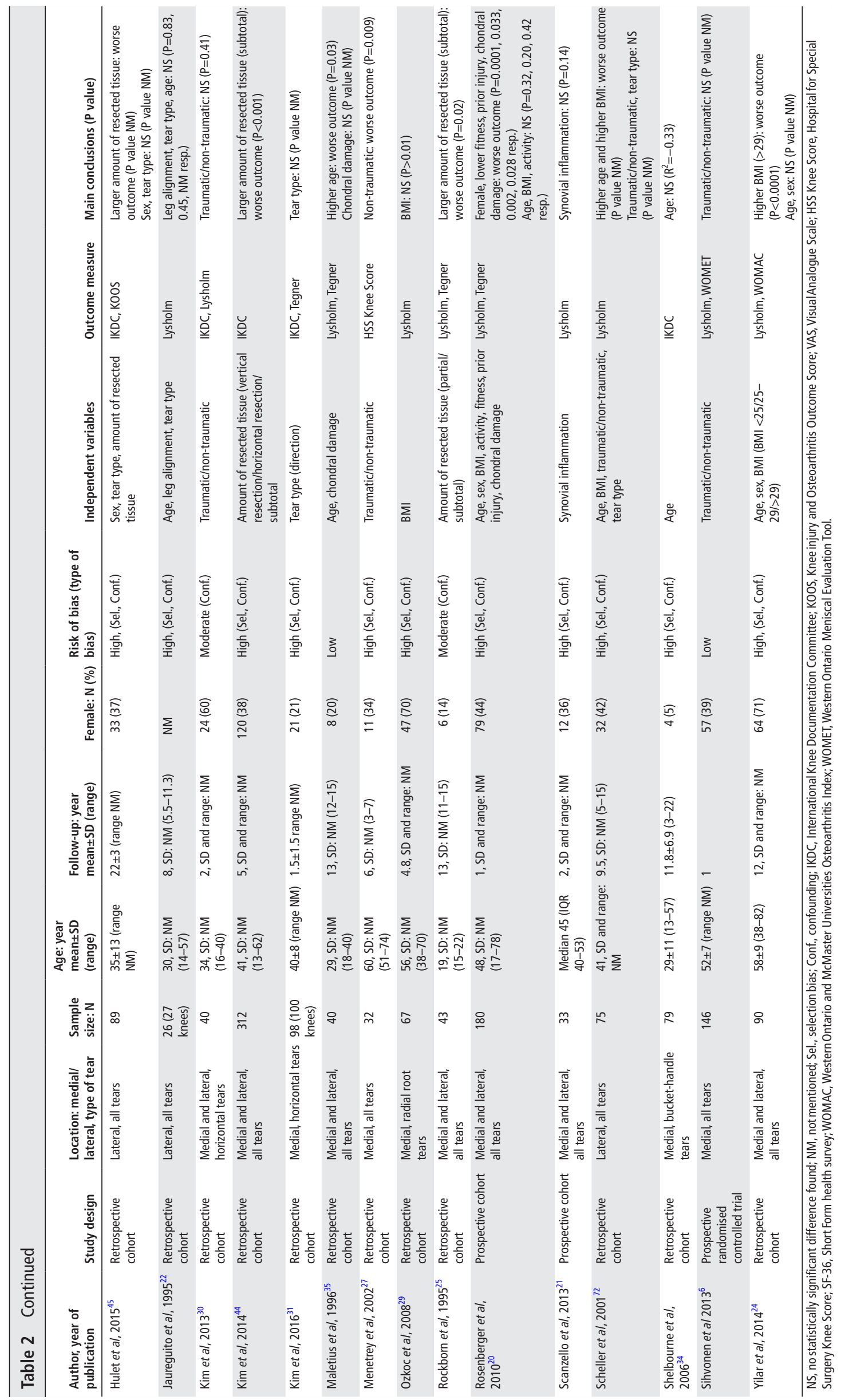


significant association between leg malalignment and clinical outcome.

\section{Chondral damage during arthroscopy}

Ten studies investigated the association between chondral damage found during surgery and clinical outcome. Three of them used the Outerbridge ${ }^{50}$ classification, two of them the International Cartilage Repair Society ${ }^{51}$ classification, and the remaining studies only mentioned whether chondral damage was found during arthroscopy or not. Six out of 10 studies reported that the presence of chondral damage predicted a worse clinical outcome, and 4 studies did not find such an association. The relationship between chondral damage and clinical outcome seems to be driven by age; when we looked at studies with patients aged above 45 years $(n=4)$, all studies reported a worse outcome for patients with chondral damage during arthroscopy. Looking at studies with patients aged below 45 years $(n=6)$, almost all studies reported no association between chondral damage and outcome. Furthermore, when specifically looking at medial meniscal tears, chondral damage seems to be a prognostic factor for worse outcome as well.

\section{DISCUSSION}

Despite the extensive heterogeneity in study design, in the definition of subgroups and in outcome measurements, several prognostic factors were found for the clinical outcome after APM. We found moderate evidence that a larger amount of resected tissue, the presence of radiological knee $\mathrm{OA}$ at baseline and a longer duration of complaints were associated with a worse clinical outcome following APM. Sex, the preoperative sport level, onset (traumatic vs degenerative) and the type of meniscal tear do not seem to influence clinical outcome. It should be noted that, the phrasing 'worse outcome' does not necessarily mean that the outcome is unsatisfactory. It means that having a specific factor is associated with a worse patient-reported outcome compared with not having this specific factor.

To the best of our knowledge, this is the first systematic review that focuses specifically on predictors for the clinical outcome following APM. Salata $e t a^{52}$ conducted a systematic review in 2010 on the radiological and clinical outcome in patients undergoing meniscectomy. The authors primarily assessed outcome measurements of APM in general, but also described some features which might influence this outcome. One of their findings was that degenerative meniscal tears are statistically significant associated with a negative postoperative outcome. This is a very relevant finding, as most APMs are performed in middleaged and elderly patients, who typically have degenerative meniscal tears. ${ }^{53-55}$ The findings of Salata et al are in concordance with Englund et $a l^{56}$ who found that degenerative meniscal tears result in worse clinical and radiological outcome after 16 years in 155 patients undergoing APM. By contrast, a recently published and methodologically robust study of Thorlund $e a^{l^{5}}$ reported no clinically relevant difference in patient-reported knee function and satisfaction between degenerative and traumatic meniscal tears after 12 months. This is in line with the results of the current systematic review, in which no difference in patient-reported clinical outcome between non-traumatic and traumatic tears was found as well. Thus, the predictive value of non-traumatic versus traumatic meniscal tears for the clinical outcome following APM is questionable and needs to be further unravelled.

Symptom duration is a relevant factor in APM for meniscal surgery. Although a short duration of symptoms ( $<6$ weeks) is one of the clinical variables that orthopaedic surgeons consider to be important in surgical decision making, ${ }^{58}$ robust evidence regarding the impact of timing awaiting for APM on clinical outcome is scarce. The fact that there is no standard definition of 'acute' and 'chronic' symptoms causes a substantial amount of heterogeneity between studies, which makes them difficult to compare. Nonetheless, in the present systematic review, moderate evidence was found that a longer duration of symptoms (longer than 3-12 months) is associated with a worse clinical outcome following APM.

A third key finding of the current systematic review concerns the amount of resected meniscal tissue during arthroscopy, which appeared to be a relevant factor in predicting the clinical outcome following APM. This is not surprising, given the critical biomechanical role of the meniscus within the knee joint. ${ }^{59}$ Our study suggests that the amount of resected meniscal tissue is negatively associated with postoperative clinical outcome following APM, in concordance with Englund et $a l^{56}$ and Salata et al..$^{52}$ More specifically, resecting $>50 \%$ of meniscal tissue, leaving $<3 \mathrm{~mm}$ meniscal width and impairing the peripheral third (the meniscal rim) were found to be associated with worse clinical outcome. In conclusion, resecting more meniscal tissue is associated with worse clinical outcome after APM.

Whereas no association was found between meniscal tears with a non-traumatic onset (compared with traumatic tears) and a worse clinical outcome following APM, our study does show that radiological knee OA at baseline is associated with a worse clinical outcome. This is in line with the results of Kirkley et $a l^{60}$ showing that arthroscopic surgery for patients suffering knee OA may not lead to satisfactory outcomes. The interesting thing is that a degenerative meniscal tear, as described earlier, does not seem to be associated with a worse clinical outcome following APM. As degenerative meniscal tears are often considered to be a signifying feature of incipient knee $\mathrm{OA},{ }^{61-63}$ one might expect that this type of tear, compared with other types of meniscal tears, has a negative association with clinical outcome as well. Further investigation into this topic, for example, using novel imaging techniques which provide quantitative information regarding the degree of meniscal degeneration ${ }^{64}$ is desired.

Another relevant knee-specific factor that we studied, is chondral damage during surgery. Symptomatic degenerative meniscal tears are frequently associated with cartilage damage to the corresponding articular surfaces. ${ }^{65}{ }^{66}$ In the current systematic review, conflicting evidence was found for the predictive value of chondral damage on clinical outcome after APM. However, subgroup analysis showed that, when looking at the studies in patients with a mean age of $<45$ years, no association was found between chondral damage and outcome. For the studies in patients with a mean age of $>45$ years, we did find that chondral damage at time of surgery is associated with a worse clinical outcome. A study by Sofu et $a l^{67}$ in which patients aged above 60 years with traumatic meniscal tears were included, reported worse pain scores for patients with chondral damage as well. Thus, it is likely that chondral damage in patients aged above 45 years has a negative influence on clinical outcome following APM, however this association needs to be further investigated.

A factor that could potential be of influence on clinical outcome is whether the tear is located in the lateral- or the medial meniscus. However, this factor was studied in only one of the included publications, which did not find an association. As a potential prognostic factor needs to be described in at least two studies, according to the best evidence synthesis principle, no conclusions regarding the predictive value of medial versus lateral meniscectomies can be drawn. This factor is particularly 
relevant as in literature, lateral meniscectomy has been reported to result in poorer postoperative outcome than medial meniscectomy. ${ }^{52{ }^{68-70}} \mathrm{~A}$ hypothesis is that the lateral meniscus is 'less conforming' than the medial meniscus after meniscectomy, resulting in an increased amount of instability and resultant force transmission to the articular cartilage. By all means, the predictive value of this factor too warrants further investigation.

A major strength of the present study is that we performed an extensive search in all relevant databases by aid of an experienced biomedical information specialist of the medical library of our institution. Furthermore, the majority of steps in this systematic review were performed in duplo, and acknowledged tools for the assessment of the risk of bias and data extraction were used. A limitation of our systematic review is that, despite the large amount of found publications, relatively few studies could be included in this systematic review. This is a consequence of our selection strategy, involving extensive exclusion criteria. To increase the a priori chance of acquiring reliable and comparable results (and potential conduct a meta-analysis), we defined concrete, well-justified and clearly stated eligibility criteria. For example, we only included articles using validated questionnaires, such as the Lysholm or International Knee Documentation Committee ${ }^{71}$ score. Publications using outcome measures such as 'percentage of satisfied patients' were therefore excluded. The rationale of this exclusion criterion is the relatively low reliability and reproducibility of non-validated patient-reported outcome measurements. Although we might have missed information about prognostic factors, we believe that this approach increased the reliability of our results.

Another limitation of this systematic review is, that only rough estimations of the effect size of the found prognostic factors could be provided. This is due to the fact that a substantial amount of heterogeneity in the definition of subgroups and outcome measurements was found. For example, the potential influence of the type of meniscal tear on clinical outcome following APM was reported in nine studies; however, none of them described a classification system for the type of tear. In fact, six of them did not provide any information regarding the definition of meniscal tear subgroups at all. Also, in many of the included studies the outcome of subgroups was poorly described. Often only P values were reported; some studies did not even provide a $\mathrm{P}$ value but only described the prognostic value of a specific factor (eg, 'No significant correlation was found between the amount of tissue resected and the subjective, clinical and radiological outcome'). ${ }^{46}$ Given the found heterogeneity and inadequately described subgroup results, pooling of study results and performing a meta-analysis were not justified. This implied that small studies might not have reported an association based on lower power while pooled results the reported association would have counted in the overall estimation for the association. By summarising findings while taking risk of bias into account, a best evidence synthesis provided conclusions based on the best available evidence. Given that most studies in the present systematic review showed a high risk of bias, only moderate and limited evidence for prognostic factors could be provided.

Despite the high amount of APMs performed worldwide, there is a lack of consensus on the indications for this procedure, particularly in younger and middle-aged patients. To enable a more evidence-based approach in surgical decision making, knowledge of the predictive value of certain patient-specific factors for the clinical outcome is essential. In this comprehensive systematic review, prognostic factors for the patient-reported outcome of APM were assessed. We have shown that based on the best available evidence,
What are the new findings?

- This is the first review that focuses specifically on predictors for the clinical outcome of arthroscopic partial meniscectomy (APM).

- The presence of radiological knee osteoarthritis (OA) and a long duration of symptoms are patient-related predictors for a worse clinical outcome after APM.

- Resecting $>50 \%$ of meniscal tissue, a non-intact meniscal rim after meniscectomy, and preserving $<3 \mathrm{~mm}$ meniscal width are intra-articular prognostic factors for a worse clinical outcome after APM.

\section{How might it impact on clinical practice in the near}

\section{future?}

In order to make an evidence-based selection of patients who would benefit the most from APM, knowledge about the predictive value of specific patient characteristics is essential.

- The patient-related prognostic factors, found in this study (longer duration of symptoms, presence of radiological knee $\mathrm{OA})$, should be considered in clinical decision making for patients with meniscal tears.

- The intra-articular prognostic factors, found in this study (resecting more meniscal tissue) should be considered during arthroscopic surgery in patients with meniscal tears.

- Additional methodologically robust studies are needed on arthroscopic meniscal surgery using validated outcome measurements and with adequate subgroups.

radiographic knee OA at baseline, a long duration of complaints and resecting more meniscal tissue during arthroscopy are associated with a worse postoperative clinical outcome. The findings could contribute to the development of a prediction model for the clinical outcome of APM, based on patient-specific factors, which could guide orthopaedic surgeons in their clinical decision making. However, within the available literature, the earlier mentioned heterogeneity and inadequately reported subgroup outcomes make it challenging to draw adequate conclusions. Therefore, there is an urgent need for more well-designed, robust clinical trials on arthroscopic meniscal surgery using validated patient-reported outcome measurements and with relevant, a priori defined subgroups. These subgroups may include a standardised and solid classification of meniscal tear type, and a standardised way of defining and classifying the duration of symptoms.

Acknowledgements The authors would like to thank Wichor Bramer (Medical Library, Erasmus MC University Medical Centre Rotterdam, The Netherlands) for assistance with designing and performing the literature search.

Contributors SME, MR, SMAB-Z and DEM conceived and designed the study. SME, DTVY and DEM performed the literature search and selected the studies. SME collected the data from all included studies. Risk of bias was assessed by SME and MR. Study outcomes were summarised and analysed by SME, MR, SMAB-Z and DEM. SME wrote the initial draft of the manuscript, and MR, DTVY, SMAB-Z and DEM made significant revisions and contributions. All authors read and approved the final manuscript.

Competing interests None declared.

Provenance and peer review Not commissioned; externally peer reviewed.

(c) Article author(s) (or their employer(s) unless otherwise stated in the text of the article) 2018. All rights reserved. No commercial use is permitted unless otherwise expressly granted. 


\section{REFERENCES}

1 Clayton RA, Court-Brown CM. The epidemiology of musculoskeletal tendinous and ligamentous injuries. Injury 2008;39:1338-44.

2 Papalia R, Del Buono A, Osti L, et al. Meniscectomy as a risk factor for knee osteoarthritis: a systematic review. Br Med Bull 2011;99:89-106.

3 Fabricant PD, Jokl P. Surgical outcomes after arthroscopic partial meniscectomy. J Am Acad Orthop Surg 2007; 15:647-53.

4 Herrlin S, Hållander M, Wange P, et al. Arthroscopic or conservative treatment of degenerative medial meniscal tears: a prospective randomised trial. Knee Surg Sports Traumatol Arthrosc 2007;15:393-401.

5 Cullen KA, Hall MJ, Golosinskiy A. Ambulatory surgery in the United States, 2006. Natl Health Stat Report 2009;28:1-25.

6 Sihvonen R, Paavola M, Malmivaara A, et al. Arthroscopic partial meniscectomy versus sham surgery for a degenerative meniscal tear. N Engl J Med 2013;369:2515-24.

7 Yim JH, Seon JK, Song EK, et al. A comparative study of meniscectomy and nonoperative treatment for degenerative horizontal tears of the medial meniscus. Am J Sports Med 2013;41:1565-70.

8 Herrlin SV, Wange PO, Lapidus G, et al. Is arthroscopic surgery beneficial in treating non-traumatic, degenerative medial meniscal tears? A five year follow-up. Knee Surg Sports Traumatol Arthrosc 2013;21:358-64.

9 Kise NJ, Risberg MA, Stensrud S, et al. Exercise therapy versus arthroscopic partial meniscectomy for degenerative meniscal tear in middle aged patients: randomised controlled trial with two year follow-up. BMJ 2016;354:i3740.

10 Khan M, Evaniew N, Bedi A, et al. Arthroscopic surgery for degenerative tears of the meniscus: a systematic review and meta-analysis. CMAJ 2014;186:1057-64.

11 Petty CA, Lubowitz JH. Does arthroscopic partial meniscectomy always cause arthritis? Sports Med Arthrosc 2012;20:58-61.

12 Moher D, Shamseer L, Clarke M, et al. Preferred reporting items for systematic review and meta-analysis protocols (PRISMA-P) 2015 statement. Syst Rev 2015;4:1.

13 Richtlijn Ontwikkeling E-B. Formulier II voor het beoordelen van een Randomised Controlled Trial (RCT). Last update: 2017 http://netherlandscochraneorg/ beoordelingsformulieren-en-andere-downloads.

14 Richtlijn Ontwikkeling E-B. Formulier III voor het beoordelen van Cohortonderzoek.Last update: 2017 http://netherlandscochraneorg/ beoordelingsformulieren-en-andere-downloads

15 Guyatt GH, Sackett DL, Sinclair JC, et al. Users' guides to the medical literature. IX. A method for grading health care recommendations. Evidence-based medicine working group. JAMA 1995;274:1800-4.

16 Slavin RE. Best evidence synthesis: an intelligent alternative to meta-analysis. J Clin Epidemiol 1995;48:9-18

17 van Tulder M, Furlan A, Bombardier C, et al. Updated method guidelines for systematic reviews in the cochrane collaboration back review group. Spine 2003;28:1290-9.

18 Aune AK, Madsen JE, Moen H. Clinical significance of condylar chondromalacia after arthroscopic resection of flap-tears of the medial meniscus. A prospective study of 93 cases. Arch Orthop Trauma Surg 1995;114:199-201.

19 Haviv B, Bronak S, Kosashvili Y, et al. Which patients are less likely to improve during the first year after arthroscopic partial meniscectomy? A multivariate analysis of 201 patients with prospective follow-up. Knee Surg Sports Traumatol Arthrosc 2016;24:1427-31.

20 Rosenberger $\mathrm{PH}$, Dhabhar FS, Epel E, et al. Sex differences in factors influencing recovery from arthroscopic knee surgery. Clin Orthop Relat Res 2010;468:3399-405.

21 Scanzello CR, Albert AS, DiCarlo E, et al. The influence of synovial inflammation and hyperplasia on symptomatic outcomes up to 2 years post-operatively in patients undergoing partial meniscectomy. Osteoarthritis Cartilage 2013:21:1392-9.

22 Jaureguito JW, Elliot JS, Lietner T, et al. The effects of arthroscopic partial lateral meniscectomy in an otherwise normal knee: a retrospective review of functional, clinical, and radiographic results. Arthroscopy 1995;11:29-36.

23 Erdil M, Bilsel $K$, Sungur $M$, et al. Does obesity negatively affect the functional results of arthroscopic partial meniscectomy? A retrospective cohort study. Arthroscopy 2013:29:232-7.

24 Yilar S, Yildirim OS. Early and late-term results of arthroscopic surgery on patients with gonarthrosis. Eurasian J Med 2014;46:102-9.

25 Rockborn P, Gillquist J. Outcome of arthroscopic meniscectomy. A 13-year physical and radiographic follow-up of 43 patients under 23 years of age. Acta Orthop Scand 1995;66:113-7.

26 Maletius W, Messner K. The effect of partial meniscectomy on the long-term prognosis of knees with localized, severe chondral damage. A twelve- to fifteen-year followup. Am J Sports Med 1996;24:258-62.

27 Ménétrey J, Siegrist O, Fritschy D. Medial meniscectomy in patients over the age of fifty: a six year follow-up study. Swiss Surg 2002;8:113-20.

28 Bin SI, Kim JM, Shin SJ. Radial tears of the posterior horn of the medial meniscus. Arthroscopy 2004;20:373-8.

29 Ozkoc G, Circi E, Gonc U, et al. Radial tears in the root of the posterior horn of the medial meniscus. Knee Surg Sports Traumatol Arthrosc 2008;16:849-54.

$30 \mathrm{Kim} \mathrm{JR,} \mathrm{Kim} \mathrm{BG,} \mathrm{Kim} \mathrm{JW,} \mathrm{et} \mathrm{al.} \mathrm{Traumatic} \mathrm{and} \mathrm{non-traumatic} \mathrm{isolated} \mathrm{horizontal}$ meniscal tears of the knee in patients less than 40 years of age. Eur J Orthop Surg Traumatol 2013;23:589-93.
31 Kim JG, Lee SY, Chay S, et al. Arthroscopic meniscectomy for medial meniscus horizontal cleavage tears in patients under age 45. Knee Surg Relat Res 2016;28:225-32

32 Han GW, Yang XL, McMullan D, et al. Structure of a tryptophanyl-tRNA synthetase containing an iron-sulfur cluster. Acta Crystallogr Sect F Struct Biol Cryst Commun 2010;66:1326-34

33 Haviv B, Bronak S, Kosashvili Y, et al. Gender effect on the outcome of partial medial meniscectomy. Orthopedics 2015;38:e925-e928.

34 Shelbourne KD, Dickens JF. Digital radiographic evaluation of medial joint space narrowing after partial meniscectomy of bucket-handle medial meniscus tears in anterior cruciate ligament-intact knees. Am J Sports Med 2006;34:1648-55.

35 Maletius W, Messner K. Chondral damage and age depress the long-term prognosis after partial meniscectomy. A 12- to 15-year follow-up study. Knee Surg Sports Traumatol Arthrosc 1996;3:211-4.

36 Bolano LE, Grana WA. Isolated arthroscopic partial meniscectomy. Functiona radiographic evaluation at five years. Am J Sports Med 1993;21:432-7.

37 Haviv B, Bronak S, Kosashvili Y, et al. Does timing of arthroscopic partial meniscectomy in stable knees matter? J Knee Surg 2017;30:47-50.

38 Covall DJ, Wasilewski SA. Roentgenographic changes after arthroscopic meniscectomy: five-year follow-up in patients more than 45 years old. Arthroscopy 1992:8:242-6.

39 Han SB, Shetty GM, Lee DH, et al. Unfavorable results of partial meniscectomy for complete posterior medial meniscus root tear with early osteoarthritis: a 5- to 8-year follow-up study. Arthroscopy 2010;26:1326-32.

40 Kellgren JH, Lawrence JS. Radiological assessment of osteo-arthrosis. Ann Rheum Dis 1957:16:494-502.

41 Fairbank TJ. Knee joint changes after meniscectomy. J Bone Joint Surg Br 1948:30B:664-70

42 Bonneux I, Vandekerckhove B. Arthroscopic partial lateral meniscectomy long-term results in athletes. Acta Orthop Belg 2002;68:356-61.

43 Chatain F, Adeleine P, Chambat P, et al. A comparative study of medial versus lateral arthroscopic partial meniscectomy on stable knees: 10-year minimum follow-up. Arthroscopy 2003;19:842-9.

$44 \mathrm{Kim} \mathrm{SJ}$, Lee SK, Kim SH, et al. Does decreased meniscal thickness affect surgical outcomes after medial meniscectomy? Am J Sports Med 2015;43:937-44.

45 Hulet C, Menetrey J, Beaufils P, et al. Clinical and radiographic results of arthroscopic partial lateral meniscectomies in stable knees with a minimum follow up of 20 years. Knee Surg Sports Traumatol Arthrosc 2015;23:225-31.

46 Hoser C, Fink C, Brown C, et al. Long-term results of arthroscopic partial lateral meniscectomy in knees without associated damage. J Bone Joint Surg $\mathrm{Br}$ 2001;83:513-6.

47 Ghislain NA, Wei JN, Li YG. Study of the clinical outcome between traumatic and degenerative (non-traumatic) meniscal tears after arthroscopic surgery: a 4-years follow-up study. J Clin Diagn Res 2016;10:RC01-4.

48 Faunø P, Nielsen AB. Meniscal resection in the athlete's knee. Scand J Med Sci Sports 1993:3:67-72.

49 Bin SI, Lee SH, Kim CW, et al. Results of arthroscopic medial meniscectomy in patients with grade IV osteoarthritis of the medial compartment. Arthroscopy 2008;24:264-8.

50 Outerbridge RE. The etiology of chondromalacia patellae. J Bone Joint Surg Br 1961:43-B:752-7.

51 van den Borne MP, Raijmakers NJ, Vanlauwe J, et al. International Cartilage Repair Society (ICRS) and Oswestry macroscopic cartilage evaluation scores validated for use in Autologous Chondrocyte Implantation (ACI) and microfracture. Osteoarthritis Cartilage 2007;15:1397-402.

52 Salata MJ, Gibbs AE, Sekiya JK. A systematic review of clinical outcomes in patients undergoing meniscectomy. Am J Sports Med 2010;38:1907-16.

53 Thorlund JB, Hare KB, Lohmander LS. Large increase in arthroscopic meniscus surgery in the middle-aged and older population in Denmark from 2000 to 2011. Acta Orthop 2014:85:287-92.

54 Englund M, Guermazi A, Gale D, et al. Incidental meniscal findings on knee MRI in middle-aged and elderly persons. N Engl J Med 2008;359:1108-15.

55 Bergkvist D, Dahlberg LE, Neuman P, et al. Knee arthroscopies: who gets them, what does the radiologist report, and what does the surgeon find? An evaluation from southern Sweden. Acta Orthop 2016;87:12-16.

56 Englund M, Roos EM, Roos HP, et al. Patient-relevant outcomes fourteen years after meniscectomy: influence of type of meniscal tear and size of resection. Rheumatology 2001;40:631-9.

57 Thorlund JB, Englund M, Christensen R, et al. Patient reported outcomes in patients undergoing arthroscopic partial meniscectomy for traumatic or degenerative meniscal tears: comparative prospective cohort study. BMJ 2017;356:j356.

58 Lyman S, Oh LS, Reinhardt KR, et al. Surgical decision making for arthroscopic partial meniscectomy in patients aged over 40 years. Arthroscopy 2012:28:492-501.

59 Englund M, Guermazi A, Lohmander SL. The role of the meniscus in knee osteoarthritis: a cause or consequence? Radiol Clin North Am 2009:47:703-12.

60 Kirkley A, Birmingham TB, Litchfield RB, et al. A randomized trial of arthroscopic surgery for osteoarthritis of the knee. N Engl J Med 2008;359:1097-107.

61 Englund M, Roemer FW, Hayashi D, et al. Meniscus pathology, osteoarthritis and the treatment controversy. Nat Rev Rheumatol 2012;8:412-9. 
62 Sihvonen R, Englund M, Turkiewicz A, et al. Mechanical symptoms as an indication for knee arthroscopy in patients with degenerative meniscus tear: a prospective cohort study. Osteoarthritis Cartilage 2016;24:1367-75.

63 Sihvonen R, Englund M, Turkiewicz A, et al. Mechanical symptoms and arthroscopic partial meniscectomy in patients with degenerative meniscus tear: a secondary analysis of a randomized trial. Ann Intern Med 2016;164:449-55.

64 Zarins ZA, Bolbos RI, Pialat JB, et al. Cartilage and meniscus assessment using T1rho and T2 measurements in healthy subjects and patients with osteoarthritis. Osteoarthritis Cartilage 2010;18:1408-16.

65 Pihl K, Englund M, Lohmander LS, et al. Signs of knee osteoarthritis common in 620 patients undergoing arthroscopic surgery for meniscal tear. Acta Orthop 2017;88:90-5.

66 Spahn G, Plettenberg H, Hoffmann M, et al. The frequency of cartilage lesions in non-injured knees with symptomatic meniscus tears: results from an arthroscopic and NIR- (near-infrared) spectroscopic investigation. Arch Orthop Trauma Surg 2017;137:837-44.

67 Sofu H, Oner A, Camurcu Y, et al. Predictors of the clinical outcome after arthroscopic partial meniscectomy for acute trauma-related symptomatic medial meniscal tear in patients more than 60 years of age. Arthroscopy 2016;32:1125-32.
68 Allen PR, Denham RA, Swan AV. Late degenerative changes after meniscectomy. Factors affecting the knee after operation. J Bone Joint Surg Br 1984;66:666-71.

69 Yocum LA, Kerlan RK, Jobe FW, et al. Isolated lateral meniscectomy. A study of twenty-six patients with isolated tears. J Bone Joint Surg Am 1979;61:338-42.

70 Jørgensen U, Sonne-Holm S, Lauridsen F, et al. Long-term follow-up of meniscectomy in athletes. A prospective longitudinal study. J Bone Joint Surg Br 1987;69:80-3.

71 van Meer BL, Meuffels DE, Vissers MM, et al. Knee injury and osteoarthritis outcome score or international knee documentation committee subjective knee form: which questionnaire is most useful to monitor patients with an anterior cruciate ligament rupture in the short term? Arthroscopy 2013;29:701-15.

72 Scheller G, Sobau C, Bülow JU. Arthroscopic partial lateral meniscectomy in an otherwise normal knee: clinical, functional, and radiographic results of a long-term follow-up study. Arthroscopy 2001;17:946-52.

73 Hulet CH, Locker BG, Schiltz D, et al. Arthroscopic medial meniscectomy on stable knees. J Bone Joint Surg Br 2001;83:29-32.

74 Haviv B, Bronak S, Kosashvili Y, et al. Arthroscopic meniscectomy of traumatic versus atraumatic tears in middle aged patients: is there a difference? Arch Orthop Trauma Surg 2016;136:1297-301. 

arthroscopic partial meniscectomy? A systematic review

Susanne M Eijgenraam, Max Reijman, Sita M A Bierma-Zeinstra, Daan T van Yperen and Duncan E Meuffels

Br J Sports Med2018 52: 514-521 originally published online November 28, 2017

doi: 10.1136/bjsports-2017-097836

Updated information and services can be found at:

http://bjsm.bmj.com/content/52/8/514

\section{References \\ Email alerting service}

\section{These include:}

\section{This article cites 72 articles, 5 of which you can access for free at:} http://bjsm.bmj.com/content/52/8/514\#ref-list-1

Receive free email alerts when new articles cite this article. Sign up in the box at the top right corner of the online article.

\section{Notes}

To request permissions go to:

http://group.bmj.com/group/rights-licensing/permissions

To order reprints go to:

http://journals.bmj.com/cgi/reprintform

To subscribe to BMJ go to:

http://group.bmj.com/subscribe/ 